\title{
DEVELOPMENT AND EVALUATION OF ORODISPERSIBLE FILMS OF LAMOTRIGINE: HYDROXYPROPYL B CYCLODEXTRIN INCLUSION COMPLEX.
}

\author{
BY \\ Manal Yassien Hamza \\ FROM \\ Department of Pharmaceutics, National Organization for Drug Control and Research \\ (NODCAR), Giza, Egypt.
}

\begin{abstract}
Orodispersible film is the type of drug delivery systems which when placed in the oral cavity disintegrates or dissolves within few seconds without water intake. This type of technology offer a convenient alternative way of dosing medication, not to special population groups, but also to the general population. The present investigation highlights on the formulation and evaluation of orodispersible films of poorly soluble antiepileptic drug lamotrigine. Dissolution characteristics of the drug was improved by forming inclusion complexes with hydroxypropyl $\beta$-cyclodextrin (HP $\beta C D$ ) employing coevaporation technique and the complexes were characterized by differential scanning calorimetry (DSC) and fourier transformation infrared spectroscopy (FTIR). Orodispersible films of LMN-HPßCD (1:1) were prepared by the solvent-casting method; using water soluble film forming polymers such as hydroxyl propyl methyl cellulose (HPMC15), polyvinyl alcohol (PVA) and Sodium carboxy methyl cellulose (SCMC).Propylene glycol and glycerin were used as plasticizers. The prepared films were evaluated for their physicochemical characteristics such as appearance, thickness, folding endurance, drug content uniformity, surface $\mathrm{pH}$, disintegration time and mechanical properties, in vitro drug release and stability studies were performed for the optimized formula according to the ICH guideline under $40^{\circ} \mathrm{C} / 75 \% \mathrm{RH}$ for three months. Amongst all formulations $\mathrm{F} 2$ films prepared with $1 \%$ w/v PVA plasticized with $3 \%$ glycerin was considered as the optimized formulation, it has the highest drug release, satisfactory in vitro disintegration time, tensile strength, \% elongation, folding endurance and stable formula. Overall results suggest that PVA is an excellent film former for antiepileptic drug lamotrigine. Therefore, orodispersible films is considered to be potentially suitable for the immediate release whenever required of lamotrigine to improve patient compliance.
\end{abstract}

\section{INTRODUCTION}

A drug can be administered via many different routes to produce a systemic pharmacologic effect. The most common method of drug administration is via the oral route is considered to be the ideal route for the administration of therapeutic agents, it is more acceptable from patient compliance aspects due to low cost and ease of administration. However, significant constraints are associated with oral administration such as hepatic first pass effect and drug degradation due to enzymes $(1,2)$. 
Lamotrigine is an antiepileptic agent shown to be effective in adjunctive treatment for refractory partial seizures and generalized seizures.It is very slightly soluble in water $\left(0.17 \mathrm{mg} / \mathrm{ml}\right.$ at $\left.25^{\circ} \mathrm{C}\right)$ with a bitter taste (3), Thus improvement of drug dissolution is desirable to improve the bioavailability of poorly water soluble drug. Among the various techniques used for the improvement in the drug dissolution characteristics, inclusion complexation with HP $\beta$-CD utilizing the co evaporation technique (4).

The intraoral rout is preferred over many other routs for easy of administration and sudden-onset of drug action is also possible .Fast dissolving drug delivery systems have started gaining popularity and acceptance as relatively new drug delivery systems, because they are easy to administer and lead to better patient compliance.These delivery systems either dissolve or disintegrate in the mouth rapidly, without requiring any water to aid in swallowing, releasing the active drug. They are useful in patients(5-7)such as pediatric, geriatric, bedridden,or developmentally disabled,who may face difficulty in swallowing conventional tablets or capsules and liquid orals or syrup, leading to ineffective therapy (8) .Due to the large surface area of the buccal mucosa being highly vascularized, drugs can be absorbed directly and can enter the systemic circulation without undergoing first-pass hepatic metabolism and obtain rapid onset of action. This advantage can be exploited in preparing products with improved oral bioavailability of molecules that undergo first pass effect(9). The objective of the present study was to improve the aqueous solubility and dissolution rate of poorly soluble lamotrigine by inclusion complexation and formulate orodispersible films of LMN-HP $\beta C D$ co-evaporate using different concentration of different water soluble film forming polymers such as hydroxyl propyl methyl cellulose (HPMC), poly vinyl alcohol (PVA)and NaCMC and clarify the effect of different plasticizers such as propylene glycol (PG) and glycerin.

\section{MATERIALS AND METHODS}

Lamotrigine(LMN)was obtained as a gift sample from Egyptian Co for Chemicals \&Pharmaceuticals S.A.E., Egypt Pharmaceuticals Pvt Ltd, Hyderabad), Hydroxy Propyl Beta-cyclodextrin (HP $\beta-C D)$ was purchased from Acros Organic, USA, Hydroxy Propyl Methyl Cellulose(HPMC E15 ) LOBA Chemie PVT.LTD, LTD Mumbai, India, Sodium carboxy methyl cellulose (SCMC), fluka Biochemico, Switzerland. and Polyvinyl alcohol (PVA)Me 31,000 Sigma Aldrich, Germany. All other reagents of analytical grade were used.

\section{Pre-formulation studies}

\section{Preparation of lamotrigine inclusion complex with HPßCD by co-evaporation technique.}

The inclusion complex formation of LMN with HP $\beta C D$ has already been reported, resulting in the significant improvement of its aqueous solubility (10). Co evaporates of LMN- HP $\beta$-CD in 1:0.25, 1:0.5 and 1:1 molar ratios were prepared as follows, methanolic solution of HP $\beta-C D$ was slowly added to alcoholic solution of LMN. The solvent was allowed to evaporate on the stirrer at a temperature between $45-50{ }^{\circ} \mathrm{C}$.The resultant solid masses were pulverized and passed through sieve No. 100 and stored in desiccators until further use . 


\section{Investigations of lamotrigine inclusion complex}

\section{1 - In vitro drug release study of lamotrigine - HPßCD complex}

Dissolution of LMN alone and its inclusion complexes in three molar ratios 1:0.25,1:0.5 and 1:1were performed in USP dissolution apparatus type I (Hanson

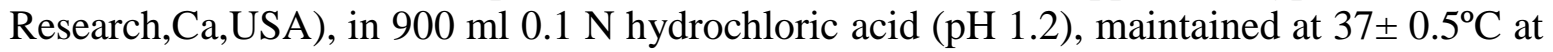
a speed of $100 \mathrm{rpm}$. At suitable time intervals, a sample $(5 \mathrm{ml})$ of the solution was withdrawn and immediately replaced with equal volume of fresh dissolution medium to maintain a constant volume for drug dissolution. The samples were filtered through a $0.45 \mu$ membrane filter and diluted to a suitable concentration with $0.1 \mathrm{~N} \mathrm{HCl}$..Absorbance of these solutions were measured at $266 \mathrm{~nm}$ using shimadzu UV/Visible beam spectrophotometer(10). The study was done in triplicate and the results obtained from dissolution studies were calculated.

\section{2- Differential scanning calorimetry (DSC) analysis}

Co evaporate which exhibited the highest solubility was examined for its endothermic or exothermic peaks aiming at declaring the formation of complex using differential scanning calorimeter, model (Shimadzu DSC-60, Japan). Accurately weighed samples of LMN, inclusion complex (1:1) and HP $\beta-C D$ complex were crimped in aluminum pans, and analyzed in an inert atmosphere of nitrogen at flow rate of $25 \mathrm{ml} / \mathrm{min}$, temperature range of 30 to $300{ }^{\circ} \mathrm{C}$, at a scanning rate of $30{ }^{\circ} \mathrm{C} / \mathrm{min}$ in air atmosphere.

\section{3- Fourier Transform Infrared (FT-IR) spectroscopy analysis}

The samples of LMN, inclusion complex (1:1) and HP $\beta-C D$ were compressed with potassium bromide pellets using a FT-IR spectrophotometer (Shimadzu 8400, Japan).The scanning range was 4000 to $400 \mathrm{~cm}^{-1}$ latresolution of $1 \mathrm{~cm}^{-1}$. An average of 20 scans is reported.

\section{Preparation of lamotrigine orodispersible films}

Various film forming polymers such as hydroxy propyl methyl cellulose ( HPMC E15), poly vinyl alcohol (PVA) and sodium carboxy methyl cellulose (SCMC) were casted as films by employing solvent casting technique. The required quantity of polymer was accurately weighed,dispersed in $10 \mathrm{ml}$ of distilled water , allowed to soak until a uniform viscous solution and stirred using magnetic stirrer for two hours at room temperature till clear solution, free from any entrapped air was obtained. All other ingredients viz., mannitol, glycerin /propylene glycol, etc.,were added to the calculated amount of preheated distilled water (80C),followed by a quantity of LMN-HP $\beta C D$ complex equivalent to $50 \mathrm{mg}$ of LMN added to the polymeric solution and stirred for 1 hour. The obtained solution was kept to equilibrate at room temperature to ensure bubble free, clear solution. A $10 \mathrm{ml}$ of this solution was casted on the casting surface (Teflon mold ) and allowed to dry in oven adjusted at $40^{\circ} \mathrm{C}$ till reaching constant weight of films. Then, films were carefully peeled off and cut according to size required for testing $\left(2 \times 3 \mathrm{~cm}^{2}\right)$ and stored in tightly closed container at 30 and relative humidity $60 \%$ in Dry heat oven (Heraeus,UT5060E,USA) until farther analysis, as shown in table 1 . 
Table 1: Composition of Lamotrigine Orodispersible Films

\begin{tabular}{|c|c|c|c|}
\hline Formulation code & $\begin{array}{c}\text { Polymer } \\
\text { Concentration } \\
\% \mathrm{w} / \mathrm{v}\end{array}$ & Polymer type & $\begin{array}{c}\text { Plasticizer } \\
\text { Concentration } \\
\% \mathrm{v} / \mathrm{v}\end{array}$ \\
\hline F1 & \multirow{6}{*}{$1 \%$} & HPMC & \multirow{3}{*}{ Glycerin $3 \%$} \\
\hline F2 & & PVA & \\
\hline F3 & & SCMC & \\
\hline F4 & & HPMC & \multirow{3}{*}{ P.G 3\% } \\
\hline F5 & & PVA & \\
\hline F6 & & SCMC & \\
\hline F7 & \multirow{6}{*}{$2 \%$} & HPMC & \multirow{3}{*}{ Glycerin $3 \%$} \\
\hline F8 & & PVA & \\
\hline F9 & & SCMC & \\
\hline F10 & & HPMC & \multirow{3}{*}{ P.G 3\% } \\
\hline F11 & & PVA & \\
\hline F12 & & SCMC & \\
\hline F13 & \multirow{6}{*}{$3 \%$} & HPMC & \multirow{3}{*}{ Glycerin 3\% } \\
\hline F14 & & PVA & \\
\hline F15 & & SCMC & \\
\hline F16 & & HPMC & \multirow{3}{*}{ P.G 3\% } \\
\hline F17 & & PVA & \\
\hline F18 & & SCMC & \\
\hline
\end{tabular}

All formulations contain 1:1 LMN- HPß-CD ( eq.to $50 \mathrm{mg}$ of LMN), Mannitol,5\% Aspartame 5\%, 0.5\% Sodium benzoate, $0.5 \%$ vanilline, $0.2 \%$ citric acid

\section{Preparation of simulated Saliva}

Sodium chloride-0.844g;Potassium chloride-1.2g;Calcium chloride dihydrate-0.193g; magnesium chloride hexahydrate-0.111g;potassium phosphate dibasic-0.342g. These ingredients were added one by one to $500 \mathrm{ml}$ of distilled water and then the volume was adjusted up to $1000 \mathrm{ml}$ with water.The $\mathrm{pH}$ was adjusted with $0.1 \mathrm{~N}$ hydrochloric acid to pH 6.2 -7.4. 


\section{Evaluation of orodispersible films}

\section{1-Visual inspection}

Properties such as homogeneity, color, transparency and surface of LMN ODFs were inspected visually (11).

\section{2-Thickness Measurements}

The thickness of the films is essential to be uniform as it is directly associated to the precision of the dose. Films were evaluated for thickness at five different locations (center and four corners) by using micrometer screw gauge (Xinchang Brillint Refrigeration Equipment Co.,Ltd, China),five samples from all the batches was withdrawn and evaluated for thickness (12).Samples with air bubbles or tears and having mean thickness variations of greater than $5 \%$ were excluded from data analysis

\section{3- Surface pH study}

The surface $\mathrm{pH}$ of the orodispersible film is calculated in order to investigate the possibility of any side effects in vivo, as acidic or alkaline $\mathrm{pH}$ may cause irritation or inflammation to the oral mucosa and it is measured to maintain the surface $\mathrm{pH}$ as close to neutral as possible. The film was placed in a petri dish and slightly moistened with the help of $1 \mathrm{ml}$ of distilled water and kept for 30 seconds, $\mathrm{pH}$ was measured by bringing the electrode in contact with the surface of the film and allowing it to stand for 1 minute. This study was performed three times for each film and the mean \pm S.D was calculated (13)

\section{4 - Drug content uniformity}

Films were placed in $100 \mathrm{ml}$ volumetric flask and dissolved in simulated saliva $\mathrm{pH} 6.8$ solutions. The contents were stirred with magnetic stirrer to dissolve the films and the volume was completed then filtered through Whatmann filter paper no. 41, to separate out the insoluble excipient. The absorbance of the solution was measured at $267 \mathrm{~nm}$ against the corresponding blank (UV visible spectrophotometer UV-1601 Shimadzu Corporation, Japan).In case of HPMC films, distilled water was used to dissolve the film and then suitably diluted with artificial saliva (pH6.8) The estimations were carried out in triplicate (14).

\section{5-Disintegration time}

There is no official guidance for disintegration test is available for orodispersible films. Films of $2 \times 3 \mathrm{~cm}^{2}$ were placed in glass petri dish and containing $10 \mathrm{ml}$ simulated salivary fluid with slight swirling at every 10 second. Time required by the film, to start to disintegrate and cut from the middle of film was noted. Test was performed in triplicate (15).

\section{6-Folding endurance}

The folding endurance is expressed as the number of folds required for breaking the specimen or developing visible cracks. This gives an indication of brittleness of the film. Films of $2 \times 3 \mathrm{~cm}^{2}$ were subjected to this test by folding the film at the same point repeatedly 
several times till a breaking was observed. The experiment was performed in triplicate and the mean was calculated (16).

\section{7-Tensile strength}

Tensile strength is defined as the maximum stress applied at a point at which the film specimen breaks. The tensile strength of the film is important to resist the mechanical movements that occur during the packing, storage and shipping of the films.Tensile strength and elongation are also significantly influenced by kind and percent of plasticizer used. Tensile strength was measured using tensile tester (Qualitest,model EMS301,USA ).Films free from air bubbles or physical imperfections were selected for tensile testing. The apparatus has two clamps, the upper one is fixed and the lower is movable. The film sample was clamped between the two clamps held $10 \mathrm{~mm}$ apart. Film was pulled by clamp at a rate of $35 \mathrm{~mm} / \mathrm{min}$. The film samples, which broke at the point of clamping and not between the clamps, were not included in the calculation. Triplicate results for each film were considered (17).

Tensile strength $(\mathrm{MPa})=$ breaking force $(\mathrm{n}) /$ Cross sectional area of sample $\left(\mathrm{mm}^{2}\right)$

\section{8-Percentage elongation}

Percentage elongation was calculated by measuring the increase in length of the film after tensile strength measurement by using the following formulae (18).

Percentage Elongation $=[\mathrm{L}-\mathrm{L} 0] \mathrm{X} 100 / \mathrm{L} 0$

Where, L was the Final length, L0 was initial length.

\section{9- In Vitro drug release study}

The in vitro release of drug from all formulations was carried out using Hanson Research device USP apparatus type II, at $37 \pm 0.5^{\circ} \mathrm{C}$ with stirring speed of $50 \mathrm{rpm}$ in 300 $\mathrm{ml}$ using simulated salivary fluid $\left(\mathrm{pH}\right.$ 6.8). Each film with dimension $\left(2 \times 3 \mathrm{~cm}^{2}\right)$ was affixed to a clip on a watch glass covered with nylon wire mesh, and put into the vessel, five milliliters samples were withdrawn at specified time intervals. The volume withdrawn was replaced by fresh volume of dissolution medium. The filtered samples were analyzed by UV at $267 \mathrm{~nm}$ and absorbance was noted. The experiment was performed in triplicate and the mean was calculated (19).

\section{Stability studies}

To study the effect of storage conditions on the optimized formulation, films were packed in a butter paper covered with aluminum foil and stored in a stability chamber to study the stability under temperature and relative humidity conditions of $40^{\circ} \mathrm{C} / 75 \% \mathrm{RH}$ for a period of 3 months. Test samples were withdrawn every month and were subjected to various tests including visual inspection of the film for, physical appearance, surface $\mathrm{pH}$, drug content, in-vitro disintegration time (20).. 


\section{3 -Results and Discussions}

\section{1- In vitro dissolution studies of LMN-hydroxy propyl betacyclodextrin complex}

It was obvious from Fig. 1 that, co -evaporates of LMN with HP $\beta$-CD release profiles of all compositions were compared and the highest extent of drug release was exhibited by the ratio of 1:1, the improvement in the drug release might attributed to the formation of inclusion complex and decrease in the drug crystalinity between the drug and $\mathrm{HP} \beta-\mathrm{CD} C \mathrm{CD}$, which is in agreement with a previously reported value (10).

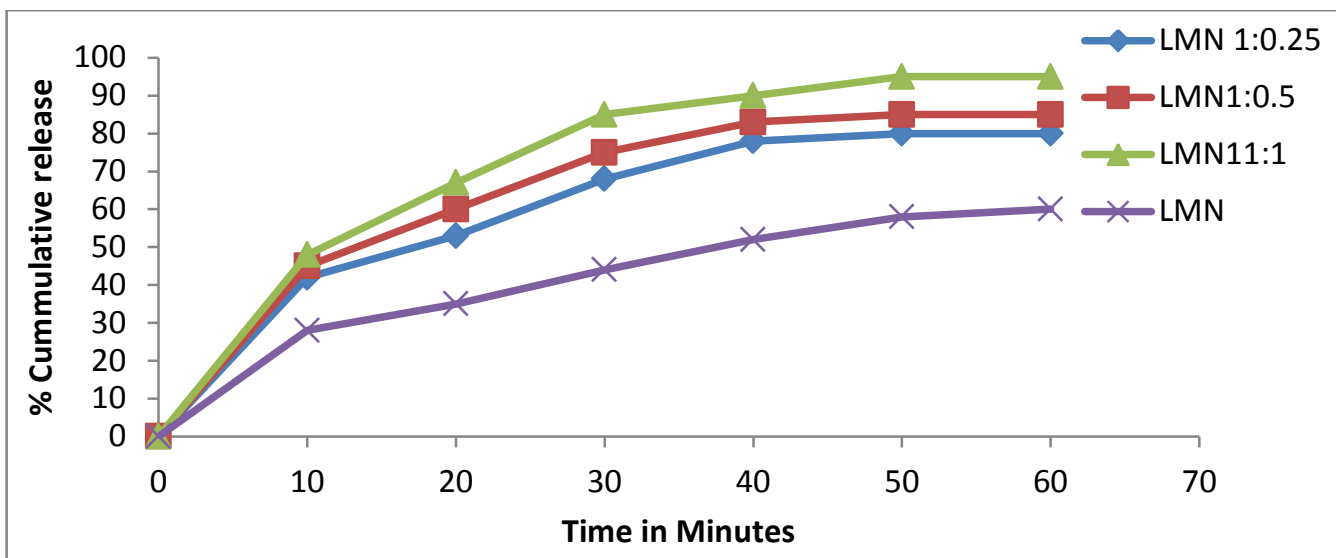

Fig.:1 In vitro dissolution profile of LMN - HPBCD Inclusion complexes

\section{2-Differential scanning calorimetry (DSC)}

It was evident from Fig.2a that, thermogram of pure LMN (showed an endothermic peak at $220.9^{\circ} \mathrm{C}$, representing the melting point of LMN .Spectra of HP $\beta$-CD (Fig. 2b), showed an endothermic peak at $61.29^{\circ} \mathrm{C}$, indicating loss of water content (Ruan et al. 2005). It was evident from Fig. $2 c$ that, LMN- HP $\beta$-CD co -evaporate 1:1 ratio showed shift of crystalline drug peak as well as the polymer, indicating that the crystalline drug was converted to amorphous state and entrapped inside the cyclodextrin cavity which might be responsible for the enhancement of drug dissolution which was further evaluated by I.R analysis . 


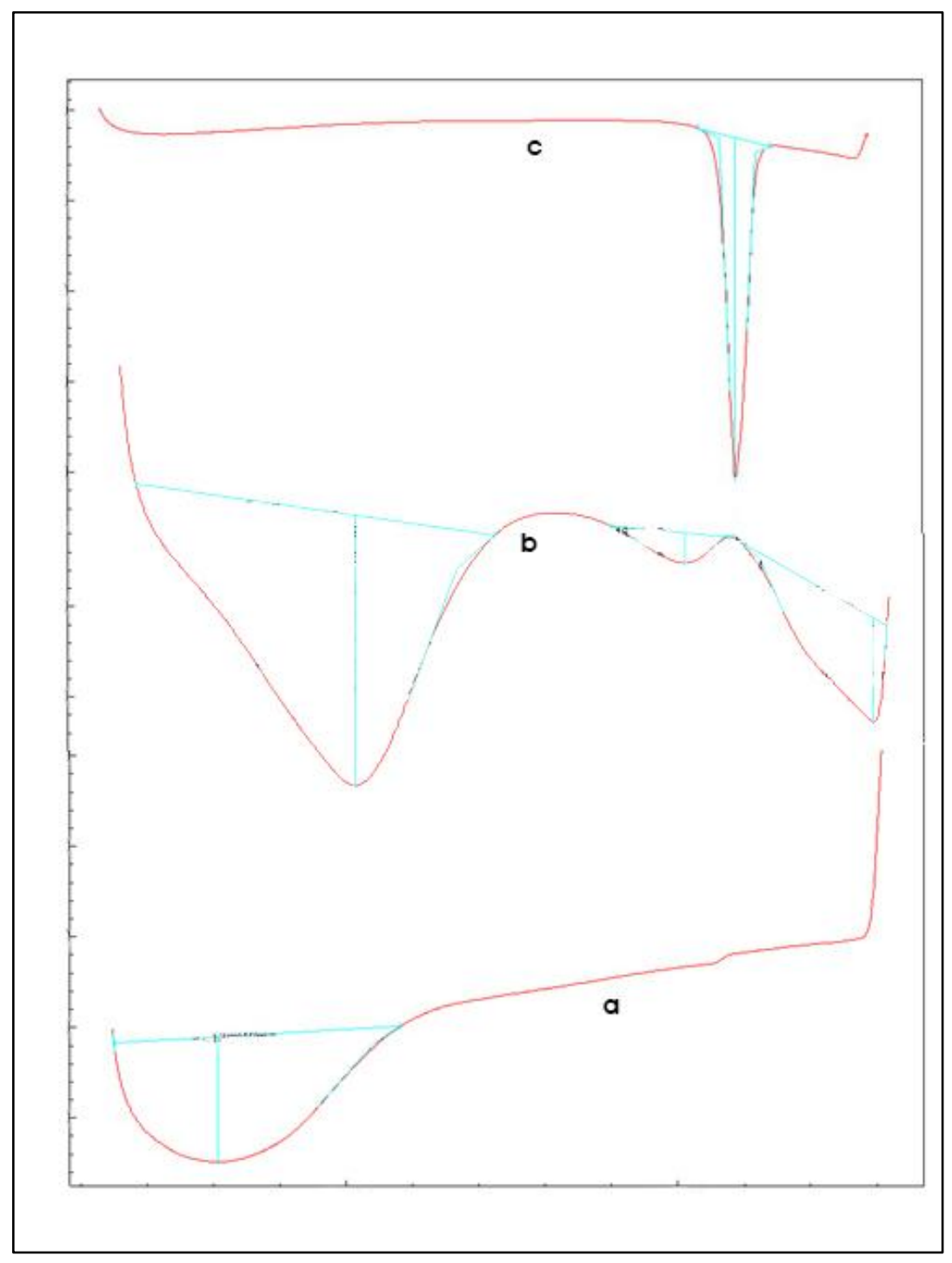

Figure 2a: a: $H P \beta-C D$ b: inclusion complex (1:1) c: lamotrigine

\section{3-Fourier Infrared spectrophotometry (FTIR)}

The IR spectrum of LMN as shown in Fig.3a is characterized by the presence of strong absorption band at $3448 \mathrm{~cm}-1$ ( $\mathrm{N}-\mathrm{H}$ stretching); $3213 \mathrm{~cm}-1$ (C-H stretching); $1620 / \mathrm{cm} ;-1(\mathrm{C}=\mathrm{N}) 1292 \mathrm{~cm}-1(\mathrm{C}-\mathrm{N}) ; 1550 \mathrm{~cm}^{-1}(\mathrm{C}=\mathrm{C}$ aromatic $) ; 1053 \mathrm{~cm}-1(\mathrm{C}-\mathrm{Cl})$; 756, 794 and $806 \mathrm{~cm}^{-1}$ (m substituted benzene) and at $806 / \mathrm{cm}$, which was indicative of presence of aromatic rings. The spectrum of HP $\beta-\mathrm{CD}$ (Fig.3b) showed prominent peaks at $3394 \mathrm{~cm}-1(\mathrm{O}-\mathrm{H}$ stretching vibrations); $2927 \mathrm{~cm}-1(\mathrm{C}-\mathrm{H}$ stretching vibrations);1639 $\mathrm{cm}-1$ (H-O-H bending); $1033 \mathrm{~cm}-1$ and $1080 \mathrm{~cm}-1(\mathrm{C}-\mathrm{H}, \mathrm{C}-\mathrm{O})$ stretching vibrations. The IR spectra of LMN- HP $\beta$-CD inclusion complex (Fig.3c) the peaks of lamotrigine at 3212 $\mathrm{cm}-1(\mathrm{C}-\mathrm{H}$ aromatic), $805 \mathrm{~cm}-1$ (msubstituted benzene) and $1052 \mathrm{~cm}-1(\mathrm{C}-\mathrm{Cl}$ aromatic) had completely disappeared,this may indicate that the halogen-substituted aromatic ring of 
the guest molecule has been entrapped in the hydrophobic cavity of the host molecule.This could also be confirmed by the shift of $1550 \mathrm{~cm}^{-1} \mathrm{TO} 1558 \mathrm{~cm}$ with low intensity of the peak and other peaks of lamotrigine intensities were smoothened and disappeared.The spectrum provides important information regarding the confirmation of inclusion complex formation of LMN- HP $\beta$-CD molecules.

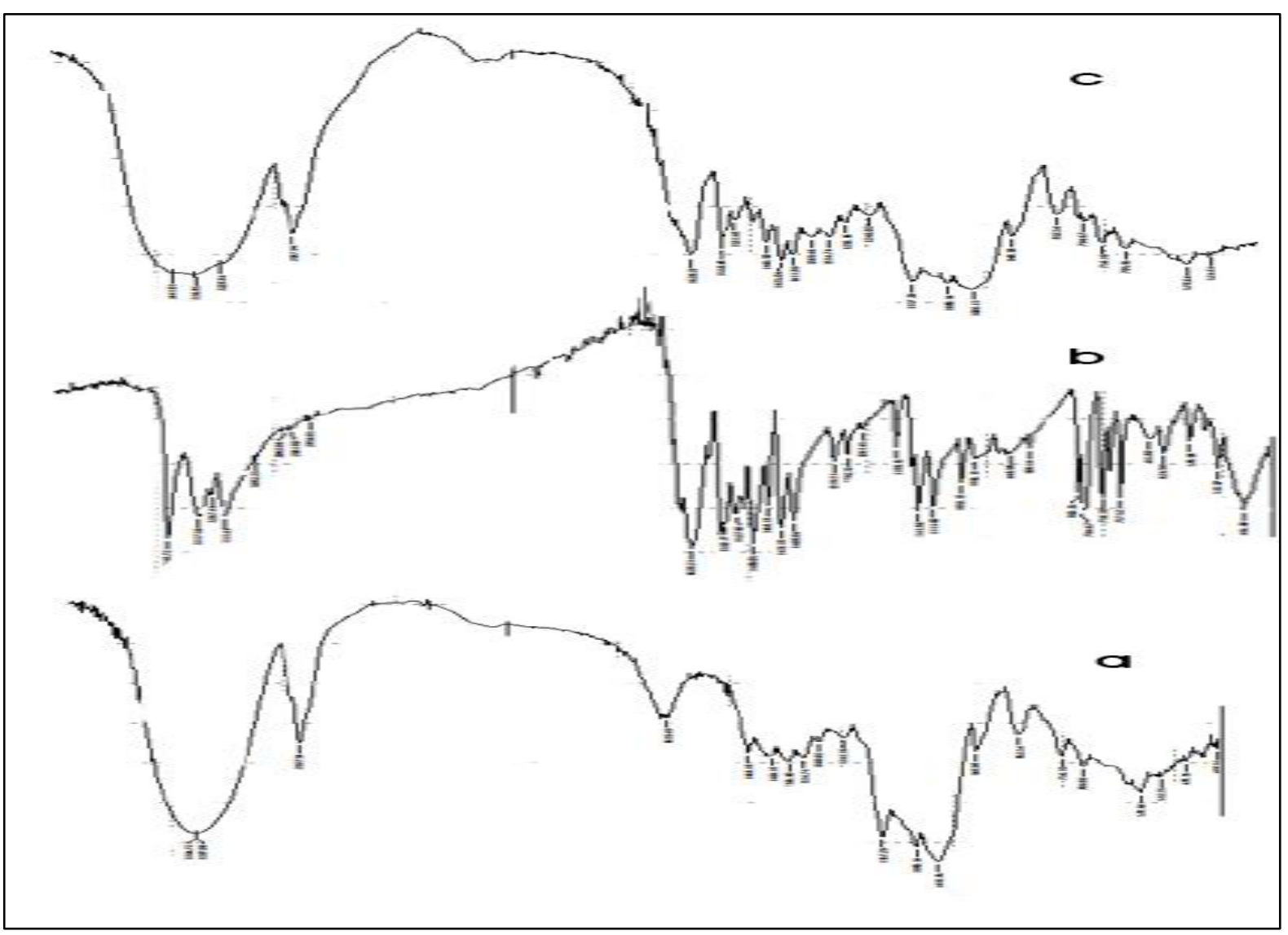

Figure 3: a: $\mathrm{HP} \beta-\mathrm{CD}$ b: lamotrigine $\mathrm{c}$ : inclusion complex (1:1)

\section{Evaluation of orodispersible films}

\section{1 -Visual inspection}

The appearance of all prepared orodispersible films which contain different film forming polymers showed homogenous, transparent, colorless, flexible, nonsticky, smooth in the texture properties with elegant appearance..

\section{2- Surface pH study}

Table 2 reported values of surface $\mathrm{pH}$ of films, it was found to be in the range of (6.2-7.1) which is within the range of salivary $\mathrm{pH}$, indicated that the films suitable and not create any kind of irritation or inflammation to oral cavity mucosa and hence, more acceptable by the patients. 


\section{3- Thickness measurement.}

It was clear from table 2 that marginal difference in the thickness was observed among each group indicated that more the amount of polymer, the higher the thickness values.

\section{4- Drug content uniformity}

From Table2 the results exhibited uniformity of drug within films and good solubilization of the drug in the formulations.

\section{5-Disintegration time}

The results illustrated in Table 2 indicated that, disintegration time of orodispersible films increased with increasing in polymer concentration (22).Furthermore, the lowest disintegration time $(13-95 \mathrm{sec})$ was observed in case of PVA films plasticized with glycerin which adsorbed more humidity leading to increase in the hydrophilic character of films, reducing the internal hydrogen bonds between the polymer chains and enlarged the internal space in the molecular structure of polymer (22). On the other hand, SCMC films showed the highest disintegration $(42-250 \mathrm{sec})$ time this may be due to formation of thick gel layer on the film surface which is capable of preventing film disintegration (24).

\section{6-Folding endure}

The results shown in Table 2 revealed that, PVA films showed satisfactory folding endure (>200 times) without breaking indicating high flexibility property ,this may be attributed to the formation of hydrogen bounds between PVA polymer and the plasticizer, resulting in flexibility to withstand rupture, while films prepared from the hydrophilic HPMC showed poor durability and flexibility this is related to weak bonds between polymer chains that cannot maintain their integrity upon folding (25).SCMC films were folded $>250$ times then, as the concentration increase films started to lose flexibility.

\section{Tensile Strength and \% elongation}

Orodispersible film should possess moderate tensile strength, high percent elongation (\% E), low EM and shorter time for disintegration with respect to their high percent of drug release (26). The results listed in table 2 revealed that,all the films showed moderate tensile strength values,.PVA films showed better tensile strength this may be due to formation of strong hydrogen bonds between hydrophilic polymer and plasticizer there by imparting the polymer flexibility to withstand rupture(27). It was also noticed that as PVA concentration increased the percentage of elongation and tensile strength of the films also increase. On the hand,SCMC flms showed lower strain values. 
Table 2: Evaluation of Lamotrigine Orodispersible Films

\begin{tabular}{|c|c|c|c|c|c|c|c|}
\hline $\begin{array}{c}\text { Formulati } \\
\text { on } \\
\text { Code }\end{array}$ & $\begin{array}{l}\% \text { Drug } \\
\text { content }\end{array}$ & $\begin{array}{c}\text { Surface } \\
\text { pH }\end{array}$ & $\begin{array}{c}\text { Thickness } \\
\text { in } \mathbf{m m} \pm \\
\text { S.D.* }\end{array}$ & $\begin{array}{c}\text { Tensile } \\
\text { Strength } \\
\text { (MPa) }\end{array}$ & $\begin{array}{c}\text { Elongatio } \\
\text { n } \\
\%\end{array}$ & $\begin{array}{l}\begin{array}{c}\text { Disintegra } \\
\text { tion }\end{array} \\
\text { time (sec) } \\
\pm \text { S.D.* }\end{array}$ & $\begin{array}{c}\text { Folding } \\
\text { endurance }\end{array}$ \\
\hline $\mathrm{F} 1$ & $98.36 \pm 1.66$ & 6.41 & $0.12 \pm 0.04$ & 1.90 & 67.90 & 32 & 240 \\
\hline $\mathrm{F} 2$ & $97.27 \pm 0.74$ & 6.61 & $0.1^{\prime} \pm 0 . \Sigma$ & 3.91 & 56.95 & 13 & $>250$ \\
\hline F3 & 91.23 & 6.7 & 0.12 & 1.43 & 54.21 & 42 & $>250$ \\
\hline $\mathrm{F} 4$ & $\begin{array}{c}101.81 \pm 4.1 \\
7\end{array}$ & 7.1 & $0.15 \pm 0.01$ & 2.30 & 72.50 & 39 & 220 \\
\hline F5 & $98.36 \pm 1.6$ & 6.63 & $0.16 \pm 0.03$ & 3.9 & $68.23 \pm 2.3$ & 18 & $>r 50$ \\
\hline F6 & $\begin{array}{c}99.21 \pm 0 \\
4\end{array}$ & 6.50 & $0.15 \pm 0.0$ & 1.82 & $79.23 \pm 2.3$ & 50 & $>250$ \\
\hline F7 & $98.36 \pm 1.66$ & 6.62 & $0.18 \pm 0.02$ & 2.53 & $75.23 \pm 2.34$ & 64 & 230 \\
\hline F8 & $98.79 \pm 0.94$ & 6.91 & $0.19 \pm 0.03$ & 3.94 . & $73.57 \pm 2.99$ & 22 & $>250$ \\
\hline F9 & $99.21 \pm 0.4$ & 6.53 & $0.18 \pm 0.0$ & 1.92 & $80.23 \pm 2.3$ & 92 & 200 \\
\hline F10 & $97.27 \pm 0.74$ & 6.94 & $0.23 \pm 0.03$ & 2.67 & 89.98 & 74 & $>250$ \\
\hline F11 & $\begin{array}{c}102.70 \pm 3.0 \\
5\end{array}$ & 7.1 & $0.22 \pm 0.01$ & 4.08 & 55.22 & 29 & $>250$ \\
\hline F12 & $99.21 \pm 0.4$ & 6.8 & $0.19 \pm 0.0$ & 2.03 & 64.21 & 140 & 220 \\
\hline F13 & $\begin{array}{c}99.21 \pm \\
0.11\end{array}$ & 6.87 & $0.25 \pm 0.0$ & 2.93 . & 62.23 & 84 & 210 \\
\hline F14 & $\begin{array}{c}99.90 \pm \\
0.13\end{array}$ & 6.40 & $0.23 \pm 0.03$ & 4.33 & 77.71 & 58 & $>250$ \\
\hline F15 & $\begin{array}{c}99.21 \pm 0 \\
4\end{array}$ & 6.43 & $0.23 \pm 0.0$ & 2.10 & 84.98 & 165 & 240 \\
\hline F16 & $\begin{array}{c}99.90 \pm \\
0.13\end{array}$ & 6.62 & $0.26 \pm 0.0$ & 3.25 & 62.24 & 102 & 240 \\
\hline F17 & $\begin{array}{c}101.81 \pm 4.1 \\
7\end{array}$ & 6.83 & $0.25 \pm 0.0$ & 4.50 & 86.20 & 95 & $>250$ \\
\hline F18 & $\begin{array}{c}99.21 \pm 0 \\
4\end{array}$ & 7.1 & $0.26 \pm 0.0$ & 2.20 & 60.69 & 250 & 220 \\
\hline
\end{tabular}




\section{8- In vitro drug release study.}

It was noticed in Fig 4(a,b,c) that, highest dissolution rate (98\% at 2 min.) was given by PVA films plasticized with glycerin (F2) which superseded the other tried ratios , this is may be attributed to the swelling of loosely bounded PVA molecules which were got hydrated rapidly weakness of the network integrity of polymer, and so erosion of the film took place leading to high solubility of PVA in water and allowing rapid release of drug along with the polymer (28).Furthermore, as the concentration of the polymer increased ,the drug release was found to be decreased due to increase in the time required for wetting and dissolving the drug molecules present in the polymer matrices. On the other hand, SCMC films showed the lowest dissolution rate as shown in Fig.(5,6 ), this may be attributed to the formation of channels followed by the formation of a stable gel layer which in turn will control the release (29).

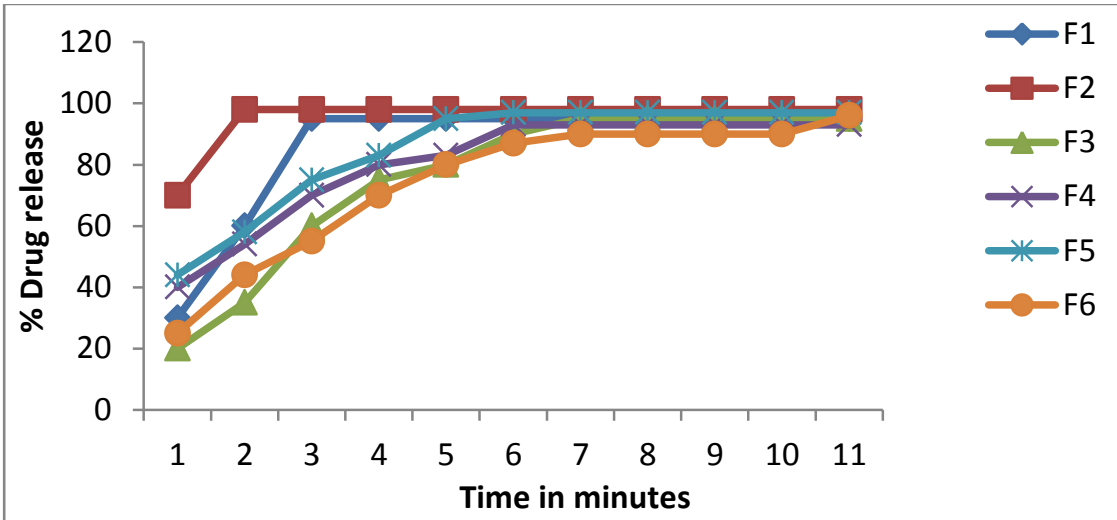

Fig.:4a In -vitro dissolution profiles of lamotrigine orodispersible

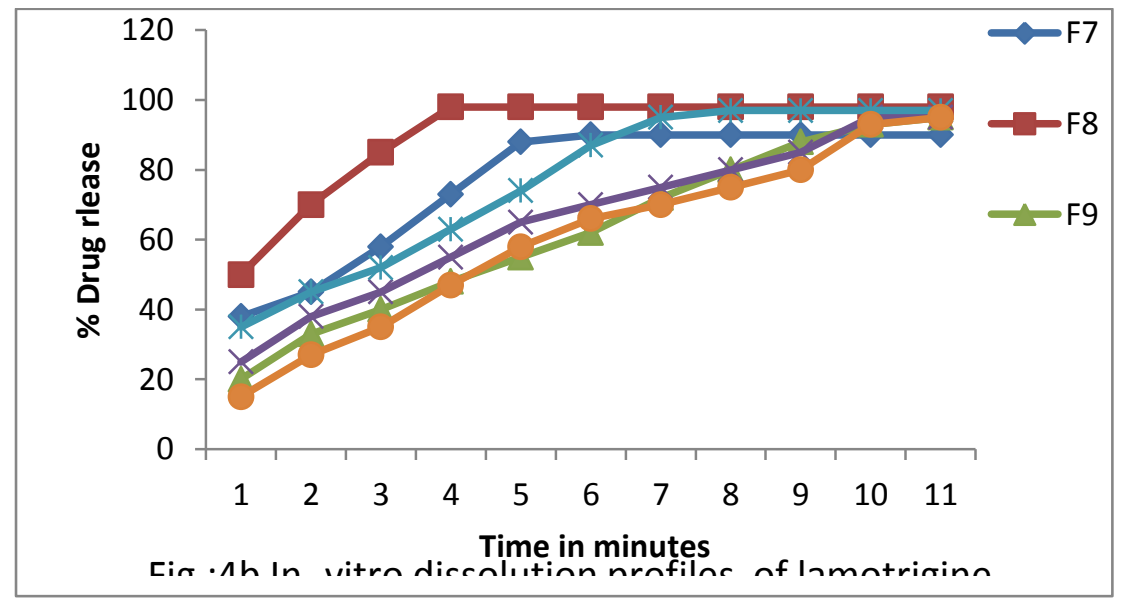




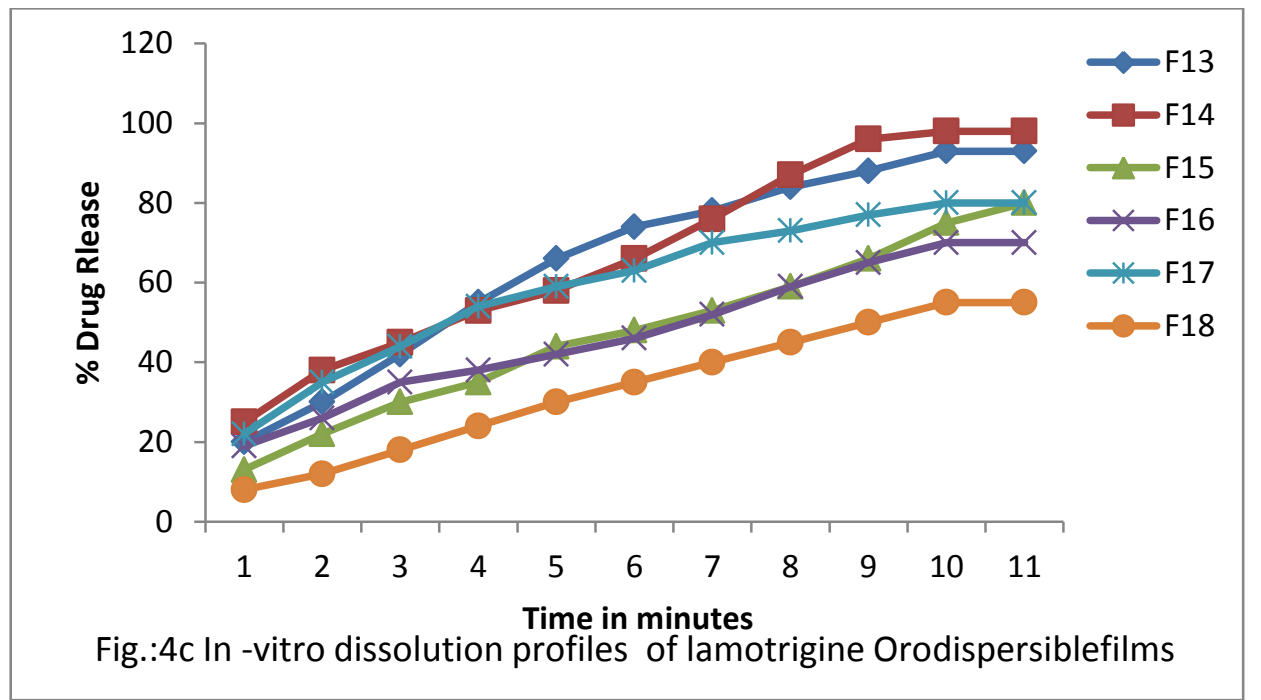

\section{9- Stability study}

It was obvious from table 3 that, the optimized formula $(\mathrm{F} 2)$ retained its original properties with no significant change in appearance, disintegration time and \% drug content.

Table 3: Stability Studies

\begin{tabular}{|c|c|c|c|}
\hline Time & Appearance & $\begin{array}{c}\text { Disintegration } \\
\text { Time(Sec) }\end{array}$ & $\begin{array}{c}\text { Drug content } \\
(\%)\end{array}$ \\
\hline zero time & $\begin{array}{c}\text { Yellowish Homogenous } \\
\text { appearance }\end{array}$ & $22 \pm .33$ & $99 \%$ \\
\hline 1 month & $\begin{array}{c}\text { Yellowish Homogenous } \\
\text { appearance }\end{array}$ & $22 \pm 33$ & $98 \%$ \\
\hline 2 month & $\begin{array}{c}\text { Yellowish Homogenous } \\
\text { appearance }\end{array}$ & $21 \pm 05$ & $98 \%$ \\
\hline 3 months & $\begin{array}{c}\text { Yellowish Homogenous } \\
\text { appearance }\end{array}$ & $22 \pm 05$ & $98 \%$ \\
\hline
\end{tabular}

\section{Conclusion}

From the aforementioned result it could be concluded that, hydroxyl propyl $\beta$-Cyclodextrin enhanced Lamotrigin Solubility through the formation of inclusion complex by coevaporation technique which were successfully incorporated into orodispersible films using different film forming polymers. Amongst all the prepared formulations F2 films prepared by $1 \%$ w/v PVA plasticized with $3 \%$ glycerin. showed significantly lower disintegration time,good folding endurance and higher percentage of drug release 
compared to HPMC and SCMC based films. The optimized films (F2) was found to be stable for three months under $40^{\circ} \mathrm{C} / 75 \% \mathrm{RH}$. Therefore, orodispersible films is considered to be potentially suitable for the immediate release whenever required of lamotrigine to improve patient compliance.

\section{REFERENCES}

Amrutkar PP, Patil SB, Todarwal AN, Wagh MA, Kothawade PD, Surawase RK (2010). Design and evaluation of taste masked chewable dispersible tablet of lamotrigine by melt granulation. International Journal of Drug Delivery: 2; 183-191.

Albha D, Sheeja K, Bhagyashri J. (2011) Design and Evaluation of Buccal Film of Dicolfenac Sodium. Int. J. Pharm. Bio. Sci., ; 1(1):p. 17-30

Chue P, Welch R, Binder C. (2004) Acceptability and disintegration rates of orally disintegrating risperidone tablets in patients with schizophrenia or schizoaffective disorders. Can J Psychiatry.; 49:701-703.

Deepthi A, Reddy BV, Navaneetha K. (2014) Formulation and Evaluation of Fast Dissolving Oral Films of Zolmitriptan. American Journal of Advanced Drug Delivery.; 2(2): 153-163.

Dixit R, Puthli S. (2009) Oral strip technology: Overview and future potential.J Control Release;139:94-107.

Garsuch V. (2009) Preparation and characterization of fast-dissolving oral films for pediatric use [Doctoral thesis]: Heinrich Heine University, Dusseldorf;.

Kai BL, Yvonne Tze FT, Kok KP.( 2012) Characterization of Oral Disintegrating Film Containing Donepezil for Alzheimer Disease. AAPS PharmSciTech; 13:134-8.

Kalyan S, Bansal M. (2012) Recent trends in the development of oral dissolving film. Int J Pharm Tech Res.; 4(2): 725-733

Khanusiya A, Charyulu RN, Prabhu P, Bhatt S, Shashtry S.( 2012) Formulation and evaluation of fast dissolving film of loratidine for sublingual use. Int J Pharm.; 3(7): $157-161$

Krause, Julia; Breitkreiyz,(2008) Improving Drug Delivery in Paediatric Medicine; Pharmaceutical Medicine. ; Volume 22 - Issue 1: 41-50.

Kumar D, Rathi L, Tripathi A, Maddheshiya YP .( 2010) A Review on Oral Mucosal Drug Delivery System. International Journal of Pharmaceutical Science and Research. ; 1(5):50-56.

M.D. Nehal Siddiqui, GarimaGarg (2011); A Short Review on "A Novel Approach in Oral Fast Dissolving Drug Delivery System and Their Patents"; Advances in Biological Research. ,; 5 (6): 291-303. 
Nafee NA, Ismail FA, Boraie NA, Mortada LM. (2003) Muchadhesive Buccal Ptaches of Miconazole Nitrate: In vitro/In vivo Performance and Effect of Ageing. Int. j. Pharm., 264:p. 1-14.

Obaidat RM, Bader A, Alrajab W. (2011) Preparation of Mucoadhesive Oral Patches Containing Tetracycline Hydrochloride and Carvacrol for Treatment of Local Mouth Bacterial Infections and Candidiasis. Sci Pharm.,; 79: 197-212.

Patel VF, Fang Liu, Brown MB (2011). Advances in oral transmucosal drug delivery. J Control Release; 153(2): 106-16.

Parmar Komal R,Satapara Vijay P, Shah Sunny R, R.( 2011) Sheth Navi Improvement of dissolution properties of lamotrigine by inclusion complexation and solid dispersion technique. Pharmazie:2.;66:119-123

Prabhu p, Mali R, Koland M,Vijaynarayan K, Souza U, Harish NM, Shastry CS, Charyulu RN. (2011) Formulation and Evaluation of Fast Dissolving Films for Delivery of Triclosan to the Oral Cavity. Int. j. Pharm. investing.,;3(2):p.99104.

Qadir KA,,Charyulu RN, Prabhu P, Bhatt S, Shastry CS.( 2012) Formulatin and Evaluation of Fast Dissolving Films of Loartidine for Sublingual Use. Int. Res. J. Pharm.,; 3(7):p.157-161.

Rahul S, Bushetti S, Shubhangi W, Bhagwat S. (2013) Development and Evaluation of Rizatriptan Patches for Buccal. World Journal of Pharmacy and Pharmaceutical Sciences.; 2(6): 5020-5045.

Seager H.(1998) Drug delivery products and the zydis fast dissolving dosage form. J. Pharm Pharmacology.; 50:375-378.

Sabar MH. (2013) Formulation and In-vitro Evaluation of Fast Dissolving Film Containing Amlodipine Besylate Solid Dispersion. International Journal of Pharmacy and Pharmaceutical Sciences.; 15 (4): 419-428.

Sultana F, Arafat M, Pathan SI.( 2013) Preparation and Evaluation of Fast Dissolving Oral Thin Film of Caffeine.International Journal of Pharmacy and Biological Sciences.; 3(1):153.

Shah SR, Parmar KR, Patel KA, Sheth NR (2009) Inclusion complexes of lamotrigine and hydroxypropyl-cyclodextrin: solid state characterization and dissolution studies.J Incl Phenom Macrocycl Chem:65:263-268).

Sumedha Bansal ,Mayank Bansal and Gopal Garg. (2013) Formulation and Evaluation of Fast Dissolving Film of Antihypertensive Drug. int.J. pharmaceutical ,chemical\& biological sci.,;3(4):p.1097-1108.

Tiwari N. (2013) A Review on: Formulation and Evaluation of Fast Dissolving Tablet. International Journal of Advanced Research in Pharmaceutical and Bio science.:3(1):60-69. 
Verena G, Jorg B (2009). Novel analytical methods for the characterization of oral wafers. Eur J Pharm and Biopharm.; 73(1): 195-201.

Wu W,Chen W, Jin Q.( 2016) Oral mucoadhesive buccal films of ciprofloxacin for periodontitis and characterization . Trop. J Pharm. Res.,;15(3):447-451.

Yatin DK, Dipen AT, Amit VP, Vipul PP.( 2013) Formulation and Evaluation of Fast Dissolving Sublingual Film of Metoprolol Succinate. Int. J. Pharma. Sci.; 4(3):140-54.

Zhang H, Zhang J, Streisand JB, (2002) Oral mucosal drug delivery: clinical pharmacokinetics and therapeutic applications. Clin. Pharmacokinetic. 41:: 661-680 .

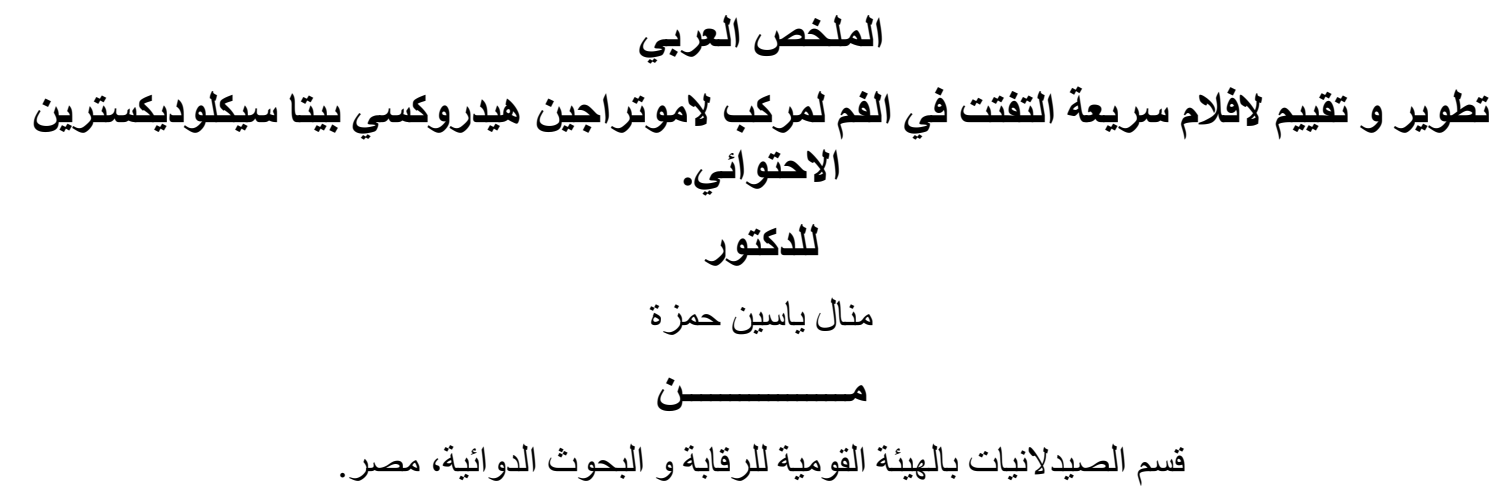

الافلام سريعة التفتت بالفم احدي انظمه توصيل للدواء التي عندما توضع بالفم تتفتت او تذوب في خلال ثوان معدودة

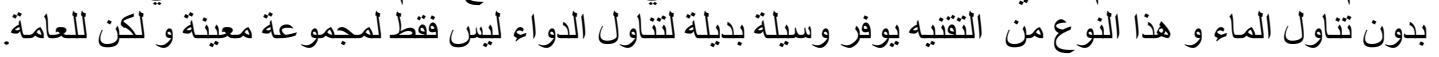

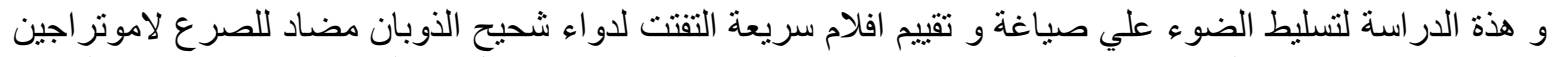

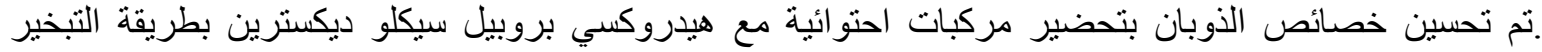

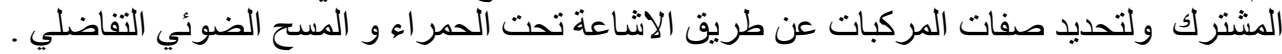

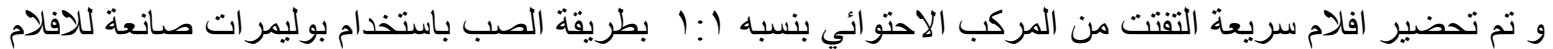

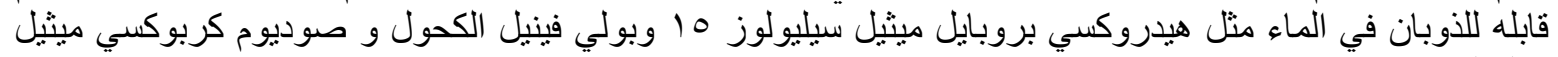
سيليولوز .

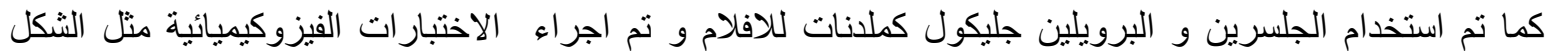

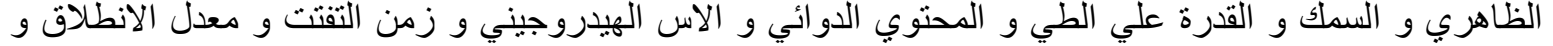

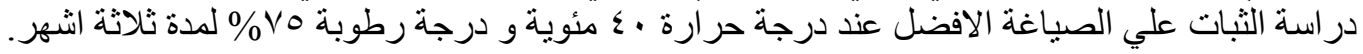

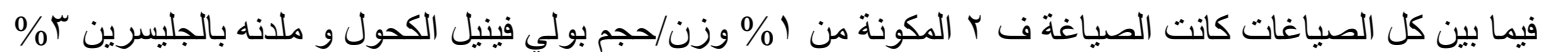

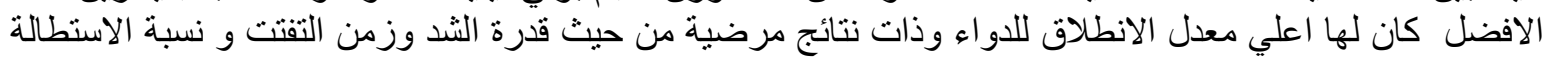

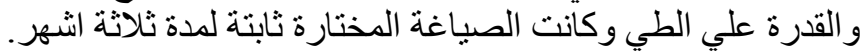
و اظهرت كل النتائج ان بولي فينيل الكحول بوليمر صانع للافلام مناسب بقوة لعقار لاموتر اجين لاستخدمه للانطلاق

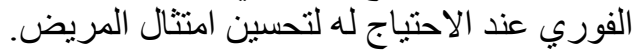

